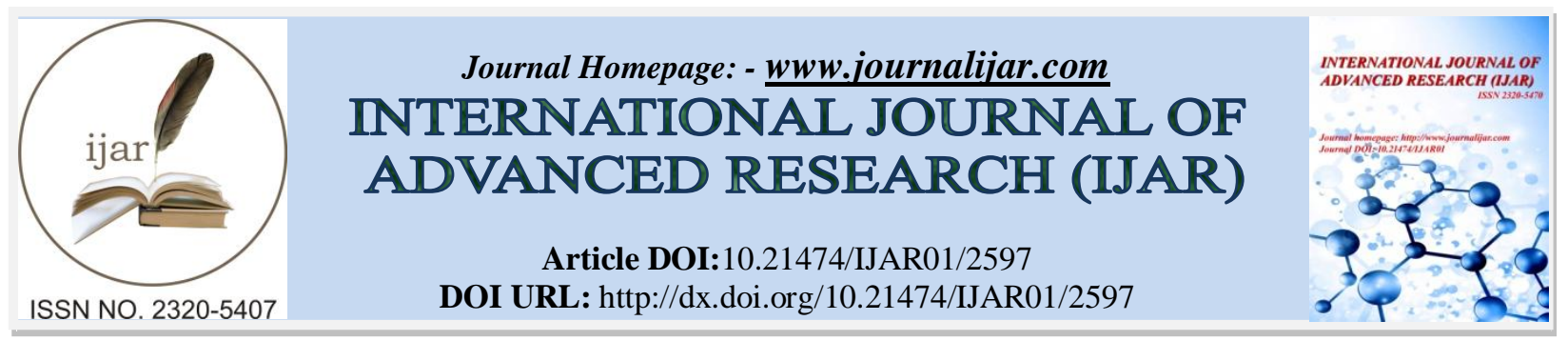

RESEARCH ARTICLE

\title{
COURVOISIERS LAW: A STUDY TO CONFIRM THE VALIDITY OF THE 'LAW' IN PRESENT SCENARIO.
}

Samir Deolekar, Anuj Sharma and Dnyaneshwar Mohare.

\section{Manuscript Info \\ Manuscript History \\ Received: 28 October 2016 \\ Final Accepted: 27 November 2016 \\ Published: December 2016 \\ Key words:- \\ Gallbladder neoplasms / pathology, \\ hepatobiliary radiology, \\ Ultrasonography, Obstructive jaundice.}

\begin{abstract}
This paper is about the full sized keyboard that is implemented using the image processing. In this type of keyboard the image of the keyboard is being projected on any plane surface and a pre calibrated camera tracks the movement of the fingers on the image and detects key being pressed. This keyboard uses embedded system and image processing to let the users work on any surface they want with a higher portability option. This technology has many application in various high tech and industrial sectors where the keyboards would be in sterile and low noise environments for example operation theatres.
\end{abstract}

Copy Right, IJAR, 2016,. All rights reserved.

\section{Introduction:-}

In 1890, Ludwig G. Courvoisier stated the famous law or sign in his book "With obstruction of the common bile duct by a stone, dilatation of gallbladder is rare. The organ is usually shrunken. With obstruction of other kinds, on the contrary, distension is the rule, shrinking occurs in only one-twelfth of these cases" 1 . In this neither the site of obstruction of the biliary tree nor the "other kinds" of obstruction elaborated. Earlier it was interpreted as well as misquoted that palpable gall bladder in a case of surgical jaundice is due to malignancy2. But Courvoisier's law does not rule out completely the association of palpable gall bladder and gall stones, particularly in CBD. With the advent of radiological imaging techniques like USG, CT scan, MRCP and endoscopic interventional studies the law seems to have many exceptions.3,7 Radiological imaging stated above, in obstructive jaundice helps in confirming the site ,cause and staging information in case of malignancy .Our study aimed at evaluating the validity of Courvoisier's law in present clinical scenario and in assessing the value of a palpable GB in determining the etiology of obstructive jaundice.

\section{Materials and Methods:-}

We did a prospective observational study which included 100 patients admitted to the department of General Surgery at a tertiary care center. The study was initiated after obtaining the approval of The Institutional Ethics Committee as per Ethical Guidelines for Biomedical Research on Human subjects, Indian Council of Medical Research,. Written informed consent was taken from everyone willing to Participate in the study. It included admitted patients from age 18 to 70 years presenting in emergency/ elective basis with obstructive Jaundice. Exclusion criteria included patients with medical jaundice and Patients with post-cholecystectomy status. The study assembled and analyzed data produced from established methods of treatment, investigation and procedures. Chisquare test and the mean of the group were used during analysis of data. 


\section{Observations and Results:-}

Out of the 100 patients, 50 were male and 50 female, an incidental finding the mean age for the presentation was 51.21 with an SD of 12.801. On comparing, Bilirubin level was found to be significantly elevated in those with palpable GB( $p$-value of 0.0001 ) . Out of the 100 study subjects 37 had benign nature of disease, 62 had malignant disease and 1 had malignancy as well as benign strictures in CBD, in whom OJ could not be ascertained to benign or malignant pathology so this subject was omitted from further analysis.

Out of the 99(100\%) subjects, a total of $43(43.43 \%)$ patients had palpable gall bladder of which $36(36.36 \%$ of total) had malignant disease. 62 (62.63\% of the total) patients had malignant cause for OJ of which $36(58.1 \%)$ patients had palpable GB. Of the 37 (37.37\% of total) patients with benign disease, 7 (18.9\%) patients had palpable GB. After applying chi-square test the association between malignant nature of disease and gall bladder palpability was found to be significant (p-value 0.0001)

Of all the investigations, USG was performed on all patients and the rest of imaging techniques were used if USG was inconclusive in establishing the diagnosis. CT scan of abdomen was performed on 89 (89.9\%) patients, MRCP on $2(2.02 \%)$ and ERCP on $10(10.1 \%)$

Out of the $99(100 \%)$ subjects, a total of 60(60.61\%) patients had distended gall bladder on USG abdomen, of which $46(46.46 \%$ of total) had malignant disease. Of the 62(62.63\% of total) patients who had malignant cause for OJ, 46(76.2\%) patients had distended GB. On applying Chi-square test, the association between distended GB and malignant nature of the disease was found to be significant. Of the $62(62.63 \%$ of total) patients with malignant OJ, $13(20.97 \%)$ patients had obstruction at or above Common Hepatic Duct (CHD), out of which $3(4.84 \%)$ had concomitant obstruction at some point distal to CHD causing GB distension on USG but was not palpable clinically. Of the 36(58.1\%) patients with malignant OJ having palpable GB, 33(91.7\%) patients had a site of obstruction below CHDand $(8.3 \%)$ had the concomitant disease at a site at or distal to cystic duct and at CHD or proximal to it. $17(34 \%)$ of patients have a malignant cause of OJ with the site of obstruction distal to CHD and Cystic duct confluence (a total of 50), didn't have a palpable gallbladder. RESULTS A palpable gallbladder in a case of obstructive is undoubtedly associated with malignant disease in a proportion merely assigned to chance.

Tables:-

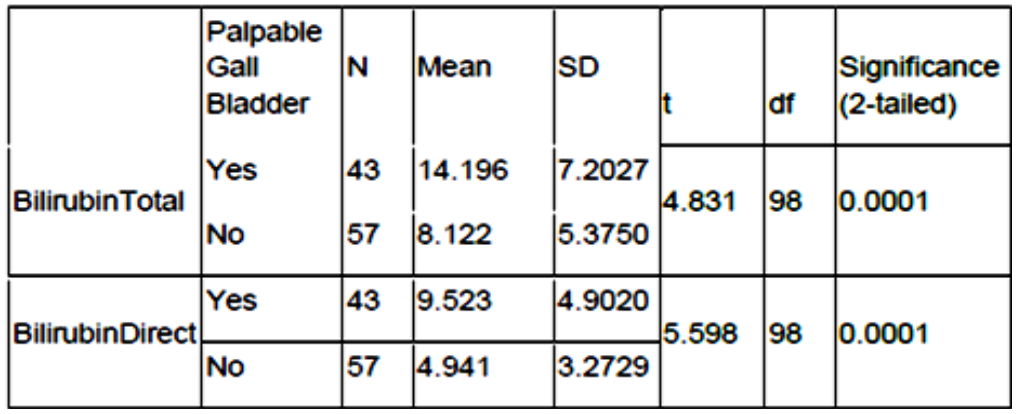

Correlation between bilirubin levels and palpable GB

\begin{tabular}{|l|l|l|}
\hline & Count & Column N \% \\
\hline $\begin{array}{l}\text { Ampulla } \\
\text { CHD }\end{array}$ & 24 & $\begin{array}{l}24.2 \% \\
\text { Cystic duct }\end{array}$ \\
\hline $\begin{array}{l}\text { Distal CBD } \\
\text { Hepatic } \\
\text { confluence }\end{array}$ & 1 & $1.0 \%$ \\
\hline Intrahepatic & 10 & $10.1 \%$ \\
\hline $\begin{array}{l}\text { Mid CBD } \\
\text { Proximal CBD }\end{array}$ & 1 & $1.0 \%$ \\
\hline Total & 28 & $20.2 \%$ \\
\hline
\end{tabular}


Percentage distribution according to site of obstruction:-

\begin{tabular}{|l|l|l|l|l|l|l|l|}
\hline \multicolumn{2}{|c|}{} & \multicolumn{3}{|l|}{ Nature of Disease } & \multirow{3}{*}{ Chi-square } & \multirow{2}{*}{ Significance } \\
\cline { 3 - 6 } \multicolumn{2}{|l|}{ Benign } & \multicolumn{2}{l|}{ Malignant } & \\
\cline { 2 - 5 } \multicolumn{2}{|c|}{} & Count & $\begin{array}{l}\text { Column } \\
\text { N \% }\end{array}$ & Count & $\begin{array}{l}\text { Column } \\
\text { N \% }\end{array}$ & & \\
\hline \multirow{4}{*}{$\begin{array}{l}\text { Palpable } \\
\text { Gall } \\
\text { Bladder }\end{array}$} & Yes & 7 & $18.90 \%$ & 36 & $58.10 \%$ & & \\
\cline { 2 - 5 } & No & 30 & $81.10 \%$ & 26 & $41.90 \%$ & \multirow{2}{*}{14.452} & 0.0001 \\
\cline { 2 - 5 } & Total & 37 & $100.00 \%$ & 62 & $100.00 \%$ & & \\
\hline
\end{tabular}

The relation between palpable GB and nature of the disease.

Figures:-
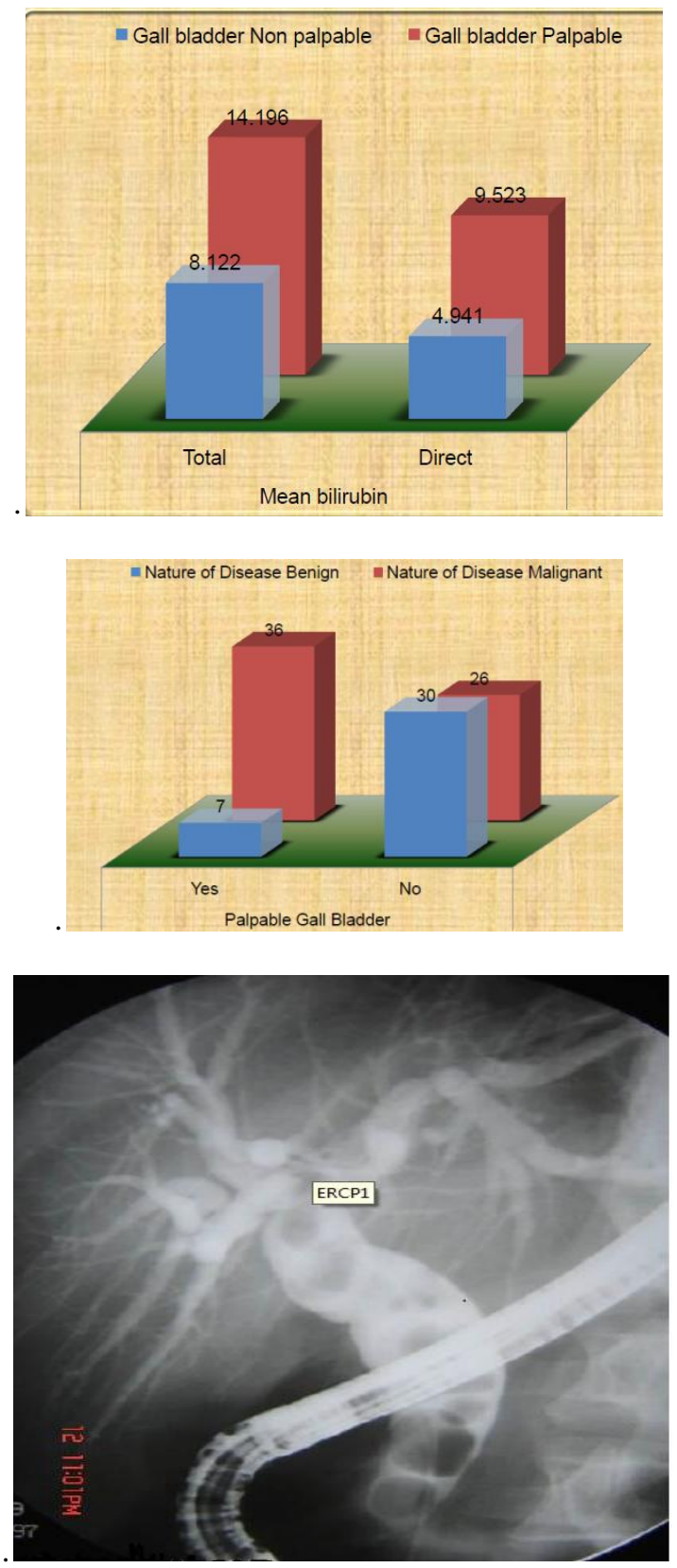

Figure 3:- ERCP Cholangiogram showing dilated CBD with multiple filling defects. 


\section{Conclusion:-}

With newer diagnostic modalities increased patient awareness and improved medical care,the number of cases violating the "LAW" have increased. Courvoisier's observation still holds true and can "help" us in finding etiology of hepatobiliary pathologies, provided it is considered a sign than a law.

\section{Discussion:-}

At the end of the discussion of 187 observed cases of obstructive jaundice, Swiss surgeon Dr. Ludwig G. Courvoisier, in the year 1890 concluded in his book 'Casuistish-statistischebeitragezurpathologie und chirugie der gallenweger' that 'with obstruction of the common duct by a stone, dilatation is rare. The organ is usually well shrunken. With obstruction from other kinds, on the contrary, distension is the rule. Shrinking occurs in only onetwelfth of cases."

This occurs probably because of the intermittent obstruction by gall bladder stones cause it to shrivel and fibrosis. On the contrary, pathologies like pancreatic or periampullary malignancies cause distension of gallbladder due to back pressure as it is of shorter duration(9). Since then this statement has been subjected to changes in wording, phrasing and grammar from time to time and it is now frequently interpreted as "a palpable gallbladder is a sign of malignancy, in a patient of obstructive jaundice2, 6. It is not known when Courvoisier's observation came to be known as "law", but it is acclaimed such as early as 190514 . Nandkarni et al. stated that 6 out of 36 cases of obstructive jaundice were an exception to this law, of which 4 had palpable gallbladder due to cholelithiasis, and 10 had malignant obstruction of lower CBD without a palpable gallbladder.15 Kaiser et al. concluded that absence of palpable gallbladder by no means excludes the diagnosis of neoplastic obstacles.3 Fournier reported 2 newly described conditions- AIDS-associated cholangiopathy and diet-induced cholecystitis as the cause of palpable gallbladder16. Studies like these have been successful in breaking the myth associated with Courvoisier's "law" that palpable gall bladder is an evidence of malignancy and vice versa. In our study, $58.1 \%$ of the patients with the malignant cause of obstructive jaundice had a palpablegall bladder. This clearly shows that Courvoisier's "law" is not absolutely inviolable, as also proved from time to time by various studies which have also proved vice versa.3, 17. Scherlock(18) says that GB is only felt in about half the patients, although at subsequent laparotomy, a dilated GB is found in three-quarters of cases. Ingelfinger19 found that at autopsy or operation, enlarged and tense GB is present in four-fifth of the cases. According to Palmer.20 Palpable GB is encountered in third of the patients with cancer of the head of 11 pancreas, in $9 \%$ in patients with biliary lithiasis. Viteri (21) found that prior to surgery, the GB is palpable in $25 \%$ of patients with cancer of the ampulla of Vater or pancreatic head. Although particular sitespecific obstructions have not been taken into considerations, $91.7 \%$ of cases in the present study with the malignant cause of obstructive jaundice having palpable gall bladder had a site of obstruction below the level of CBD .

Although these studies do not support the validity of Courvoisier's law, they don't rule out its significance as well(24). The exception to Courvoisier's laws are as follows:

Tumors at or above CBD, Metastatic lymph node at porta, post cholecystectomy, primary CBD stone, Mirrizi's syndrome, double impaction of gallstones i.e. at cystic duct and CBD, oriental cholangiohepatitis, chronic pancreatitis, pancreatic duct calculi The problem which seems to be associated with Courvoisier's observation which was initially considered as law with rare exceptions is that with advanced imaging techniques around more case reports of various pathologies causing obstructive jaundice, previously acclaimed to be "rare causes" have now been found to be relatively common as also is evident in our study. The number of cases violating this law has been increasing from $8 \%$ as noted originally by Courvoisier 5 to $23.1 \%$ by Nadkarni et al(15) and few other studies.(1624 )This increase in a number of exceptions is due to increased rate of detection owing to advanced imaging techniques ,increased patient awareness and vigilance amongst medical personnel in picking subtle clinical signs. As in our study, using imaging techniques, detection of distended gall bladder has increased by $33.25 \%$ or 1.33 times in patients with malignant disease and $100 \%$ or 2 times in patients with benign disease. Still, the association between distended gall bladder and nature of disease-causing obstructive jaundice to be malignant is statistically significant. This explains the reason why a number of exceptions to Courvoisier's "law" is increasing in present clinical scenario, as also mentioned earlier. Hence, after reviewing the literature and studying the results of a present study it comes to notice that a palpable gallbladder in a case of obstructive is undoubtedly associated with malignant disease in a proportion to be merely assigned to chance. The same was concluded by Courvoisier's in his book in 1890 . But the discrepancy arises when his observations were assigned the status of law, the origin of which is unknown but can be dated back to as early as 1905 . When it is called as a law, it is expected to be flawless and without exceptions, which is not the case with Courvoisier's law, as it has got many exceptions, reported from time to time. 
- Rather than considering the observation made by Courvoisier in patients with obstructive jaundice as law, if it is considered as a sign, then the discrepancy as to whether Courvoisier's law is valid in present clinical scenario or not doesn't arise. Rather it would definitely help in arriving at a diagnosis, albeit by modern imaging techniques.

\section{Bibliography:-}

1. Ransom HK. Carcinoma of Pancreas. Am J of Surg 1928; 40:246-81

2. Fitzgerald JE, White MJ, Lobo DN. Courvoisier's gallbladder: law or sign? World J Surg. 2009 Apr:33(4):88691

3. Kaiser MH, Smith FP, Schein SP, Zeppa R, Exocrine Tumors of the Pancreas, Bockus Gastroenterology, Philadelphia, W. B. Saunders Company, Fourth Edition 1985;6: 4094-109.

4. Munzer D. Assessment of Courvoisier's law. Saudi J Gastroenterol 1999;5 :106-12

5. Courvoisier's LJ. Casuistisch-statistischebeitragezurpathologie und chirurgie der gallenweger. Leipzig: Vogel; 1890

6. Warrell D, Cox T, Firth J, Benz E, editors. Oxford textbook of medicine. 4thed. England: oxford University Press; 2004.

7. Chung RS. Pathogenesis of the "Courvoisier's gallbladder". Dig Dis Sci1983;28(1):33-8. [PubMed]

8. Martin DF, Laasch HU. The biliary tract. In: Grainger RG, Allison D eds. Grainger \& Allison's Diagnostic Radiology- A textbook of medical imaging, 4th ed. Churchill Livingstone, Harcourt publishers limited, London: 2001.

9. Geier A, Gartung C, Dietrich CG, Lammert F, Wasmuth HE, Matern S [Diagnosis of cholestatic disorders]. Med Klin (Munich). 2003 Sep 15;98(9):499-509. [Article in German] PMID: 14551707

10. Yamakawa T, Honda H. [Image diagnostics for carcinoma of the biliary tract]. Gan To Kagaku Ryoho. 1991 Jul;18(8):1258-63. [Article in Japanese] PMID: 2069395 EUS

11. Sharma MP, Ahuja V. Aetiological spectrum of obstructive jaundice and diagnostic ability of ultrasonography: a clinician's perspective. Trop Gastroenterol. 1999 Oct-Dec20(\$):167-9

12. Khurram M, Durrani AA, Hasan Z, Butt AUA, Ashfaq S. Endoscopic retrograde cholangiopancreatographic evaluation of patients with obstructive jaundice. J Coll Physicians Surg Pak 2003;13:325

13. Alam AM, Rudra G, Lutfi Shuaib IL, Dhiraj S, Pradeep V, Sunil P. Biliary Obstruction Evaluation With Direct Cholangiography. The Internet Journal of Radiology.2007 Volume 5 Number 2.

14. Moyniham BGA. Gallstones and their surgical treatment. 2nd ed. Philadelphia: WB Saunders; 1905.

15. Nadkarni KM, Jahagirdar RR, agzi RS, Pinto AC, Bhalerao RA. Surg Obstruct Jaundice 1981;27:33-16. Fournier AM, Michel J. Courvoisier's sign revisited: two patients with the palpable gallbladder. Southern Med J 1992; 85:548-

16. Orloff MJ, Marassi NP, Tumors of the extra-hepatic bile ducts, Bockus Gastroenterology, Philadelphia, W.B. Saunders Company, Fourth Edition 1985;6:3771-81.

17. Scherlock S. Dooley J. Diseases of the liver and the biliary system, London, Blackwell Scientific Publications, Ninth Edition 1993;600

18. Ingelfinger FJ. The diagnosis of cancer of the pancreas, New ENG J Med 1946;235:653.

19. Palmer ED. Clinical Gastroenterology, Washington, D.C. Hoeber-Harper. 1957;526-64.

20. Viteri AL, Courvoisier's Law and evaluation of the jaundiced patient. Texas Med1980;76:60-1

21. Kauer JT, Glenn F. Carcinoma of the pancreas. Arch Surg 1941;42:141-55.

22. Schnedorf JG, Orr TG. Fifty-two proven cases of carcinoma of pancreas and ampulla of Vater, with special references to carcinoma. Ann Surg1941;114:603-11.

23. Schlippert W, Lucke D, Anuras S, Christensen J. Carcinoma of the papilla of Vater. A review of fifty- seven cases. Am J Surg 1978;135(6):763-70.

24. Morgenstern L, Ludwig G. Courvoisier and Courvoisier's Law. Surg Gynec Obstet 1960;110:383-4 